\title{
ISOLASI DAN IDENTIFIKASI SENYAWA FLAVONOID EKSTRAK ETANOL PANDAN HUTAN JENIS BARU FREYCINETIA SESSILIFLORA RIZKI
}

\author{
Ade Ferdinan*, Fitri Sri Rizki \\ Akademi Farmasi Yarsi Pontianak \\ *: ferdin.nay@gmail.com
}

\begin{abstract}
ABSTRAK
Kalimantan Barat merupakan daerah tropis yang wilayahnya terdiri dari daerah berawa, dataran tinggi, dataran rendah dan pegunungan yang mana sangat berpotensi sebagai tempat hidup bagi tanaman-tanaman obat. Salah satu jenis tanaman pandan hutan jenis baru dengan nama latin Freycinetia sessiliflora Rizki yang ditemukan di Gunung Passi Singkawang belum terekspos ilmiah secara luas. Penelitian ini bertujuan untuk mengisolasi senyawa flavonoid yang terdapat pada ekstrak etanol pandan dengan ekstraksi maserasi menggunakan etanol $96 \%$.

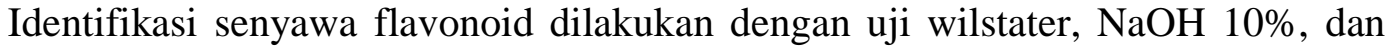

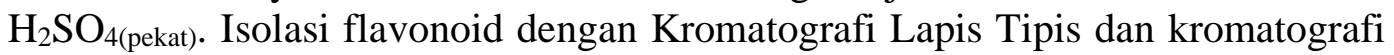
kolom. Hasil beberapa uji menunjukkan adanya senyawa flavonoid yang terkandung dalam ekstrak etanol pandan Freycinetia sessiliflora Rizki
\end{abstract}

Kata Kunci : Pandan hutan jenis baru, isolasi, Identifikasi, kromatografi

\begin{abstract}
West Kalimantan is a tropical area whose territory consists of swampy areas, highlands, lowlands, and mountains which have the potential to be a place to live for medicinal plants. One of the new types of forest pandanus plant, Freycinetia sessiliflora Rizki, found on Mount Passi, Singkawang, has not been widely exposed to scientific knowledge. This study aims to isolate the flavonoid compounds contained in pandan ethanol extract by maceration extraction using $96 \%$ ethanol. Identification of flavonoid compounds was carried out by wiltrater, $10 \% \mathrm{NaOH}$, and $\mathrm{H}_{2} \mathrm{SO}_{4}$ (concentrated) tests. Isolation of flavonoids by Thin Layer Chromatography and Column Chromatography. The results of several tests showed that there were flavonoids contained in the ethanol extract pandanus Freycinetia sessiliflora Rizki.
\end{abstract}

Keywords: Freycinetia sessiliflora Rizki, isolation, identification, chromatography

\section{PENDAHULUAN}

Salah satu jenis tanaman yang ada di Kalimantan Barat diantaranya merupakan tanaman yang berasal dari genus Freycinetia yakni tanaman pandan hutan jenis baru (Freycinetia sessiliflora Rizki.) yang ditemukan di
Gunung Passi, Singkawang dan keberadaanya masih belum terekspos secara luas dan belum banyak diteliti. Berikut gambar species pandan Hutan baru yang ditemukan. 


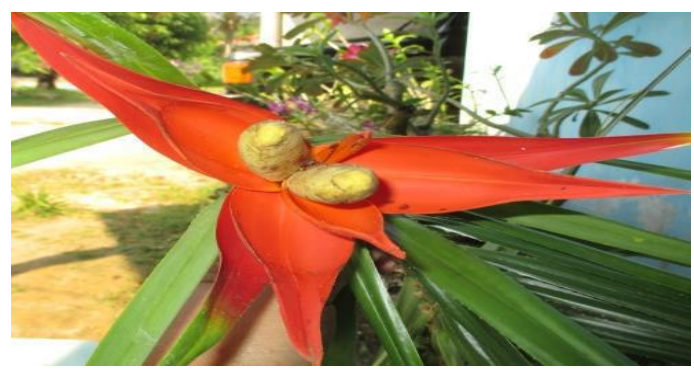

Gambar 1. Pandan hutan species baru

Penelitian yang telah

dilakukan sebelumnya bahwa ekstrak etanol daun pandan jenis baru mampu menghambat pertumbuhan bakteri Streptococcus mutans dan Eschericia coli. Daya hambat yang dihasilkan pada bakteri Streptococcus mutans dengan konsentrasi 5\% sebesar 10,1 mm. Sedangkan pada bakteri Escherichia coli, didapatkan hasil rata-rata hambatan konsentrasi 5\% sebesar 12,2 $\mathrm{mm}$ dan dalam ekstrak tersebut ditemukan kandungan kimia flavonoid, tanin, terpenoid dan saponin ${ }^{1}$. Sejumlah tanaman mengandung flavonoid telah dilaporkan memiliki aktivitas antioksidan, antibakteri, antivirus, antiradang, antialergi, dan antikanker ${ }^{2}$. Artanti, et al (2006) menyatakan bahwa sejumlah tanaman obat yang mengandung flavonoid telah dilaporkan memiliki aktivitas antioksidan, antibakteri, antivirus, antiradang, antialergi dan antikanker ${ }^{3}$. Senyawa flavonoid adalah senyawa yang mengandung $\mathrm{C}_{15}$ terdiri atas dua inti fenolat yang dihubungkan dengan tiga satuan karbon. Darsana (2012) menyatakan mekanisme kerja dari flavonoid dalam menghambat pertumbuhan bakteri antara lain bahwa flavonoid menyebabkan terjadinya kerusakan permeabilitas dinding sel bakteri dan mampu menghambat motilitas bakteri $^{4}$. Penelitian ini bertujuan mengisolasi Isolasi golongan senyawa flavonoid pada ekstrak etanol pandan jenis baru Freycinetia sessiliflora Rizki.

\section{METODE PENELITIAN}

Alat

Alat yang digunakan seperangkat alat gelas, wadah maserasi, plat kromatografi lapis tipis (KLT), lampu UV penampak bercak $254 \mathrm{~nm}$ dan $366 \mathrm{~nm}$, neraca analitik, alat kromatografi kolom, chamber, pipa kapiler, rotary evaporator, kertas saring.

\section{Bahan}

$\begin{array}{rrr}\text { Bahan } & \text { yang } & \text { digunakan } \\ \text { pandan jenis baru } & \text { (Freycinetia }\end{array}$ 
sessiliflora Rizki), etanol 96\%, larutan asam klorida $(\mathrm{HCl})$, serbuk magnesium $(\mathrm{Mg})$, larutan natrium hidroksida $(\mathrm{NaOH}) 10 \%$, asam sulfat $\left(\mathrm{H}_{2} \mathrm{SO}_{4}\right)$ pekat, silika gel 60 , nbutanol, asam asetat glasial, quersetin, Aquadest

\section{Ekstraksi}

Sejumlah sampel dimasukkan kedalam bejana maserasi dibiarkan cairan penyari merendam seluruh serbuk simplisia sambil sesekali diaduk, kemudian disaring untuk mengambil filtratnya. Filtrat diuapkan dengan rotary evaporator sehingga diperoleh ekstrak kental etanol ekstrak etanol pandan jenis baru Freycinetia sessiliflora Rizki.

\section{Skrining Fitokimia Flavonoid}

1. Uji wilstater

Ekstrak etanol pandan jenis baru Freycinetia sessiliflora Rizki ditambahkan 2-4 tetes larutan $\mathrm{HCl}$ pekat dan 2-3 potong kecil logam Mg. Perubahan warna yang terjadi diamati dari kuning tua menjadi orange.

2. Uji dengan $\mathrm{NaOH} 10 \%$

Sejumlah ekstrak etanol pandan jenis baru Freycinetia sessiliflora Rizki ditambahkan 2-4 tetes larutan $\mathrm{NaOH} 10 \%$, perubahan warna yang terjadi diamati dari kuning tua menjadi kuning muda.

3. Uji dengan $\mathrm{H}_{2} \mathrm{SO}_{4}$ (pekat)

Sejumlah ekstrak etanol pandan jenis baru Freycinetia sessiliflora Rizki ditambahkan 2-4 tetes larutan $\mathrm{H}_{2} \mathrm{SO}_{4}$ (pekat). Perubahan warna yang terjadi diamati dari kuning tua menjadi coklat.

\section{Kromatografi lapis tipis}

Ekstrak mengandung flavonoid dilarutkan dengan pelarut yang digunakan, kemudian sampel ditotolkan pada plat KLT dan diletakkan di dalam bejana yang telah dijenuhkan dengan eluen, plat KLT dibiarkan di dalam bejana tesebut hingga eluen sampai pada tanda batas yang telah tentukan. Plat KLT kemudian dikeluarkan dari bejana dan dikering anginkan lalu disinari di bawah lampu ultraviolet pada panjang gelombang $254 \mathrm{~nm}$ dan $366 \mathrm{~nm}$.

\section{Kromatografi kolom}

Ekstrak dilarutkan dengan sedikit pelarutnya kemudian dimasukkan dalam yang telah disiapkan, fase gerak ditambahkan secara terus menerus sampai terjadi pemisahan. Eluat ditampung pada 
penampung fraksi setiap $3 \mathrm{~mL}$. Eluat yang diperoleh dilihat pola nodanya pada KLT. Data yang diperoleh dianalisis secara deskriptif meliputi identifikasi dengan penambahan reagen sebanyak 3 kali replikasi, ditandai dengan perubahan warna yang dihasilkan. Ekstrak yang positif mengandung golongan senyawa aktif dilanjutkan dengan kromatografi lapis tipis (KLT) dan kromatografi kolom dengan eluen yang sesuai.

\section{HASIL DAN PEMBAHASAN}

Ekstraksi dan Skrining Fitokimia Flavonoid

Maserasi adalah salah satu metode pemisahan senyawa dengan cara perendaman menggunakan pelarut organik pada temperatur ruangan. Pelarut yang digunakan adalah etanol $96 \%$. proses maserasi (perendaman ) sampel tumbuhan akan terjadi pemecahan dinding dan membran sel akibat perbedaan tekanan antar di dalam dan di luar sel, sehingga metabolit sekunder yang ada dalam sitoplasma akan terlarut dalam pelarut. pelarut yang mengalir ke dalam sel dapat menyebabkan protoplasma membengkak dan bahan kandungan sel akan larut sesuai dengan kelarutannya ${ }^{5}$. Berikut hasil skrining fitokimia.

Tabel 1. Hasil Skrining Fitokimia Flavonoid

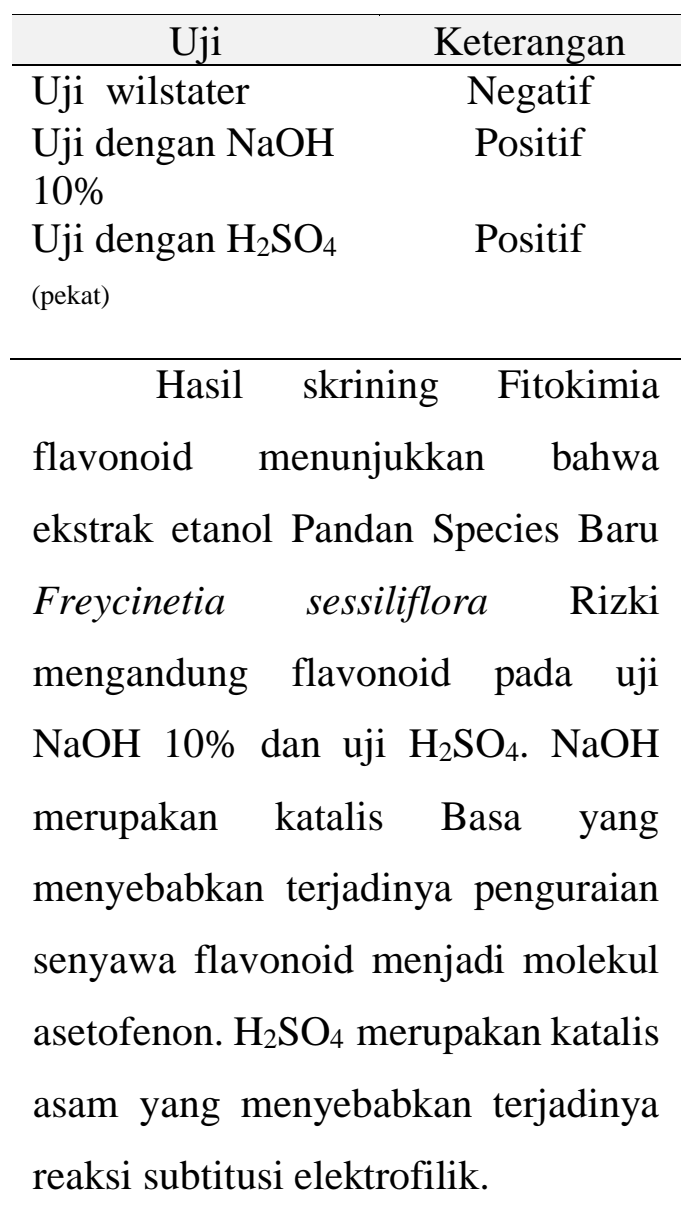

\section{Isolasi Flavonoid}

Ekstrak etanol Pandan Species Baru Freycinetia sessiliflora Rizki yang positif mengandung flavonoid kemudian dipisahkan secara kromatografi lapis tipis dan kramografi kolom. ekstrak etanol Pandan Species Baru Freycinetia sessiliflora Rizki dipisahkan dengan 
KLT untuk memperoleh eluen yang sesuai sehingga dapat memisahkan senyawa-senyawa pada sampel dengan melihat noda dan dibandinngkan dengan standar kuersetin. ekstrak etanol Pandan Species Baru dapat dipisahkan dengan baik menggunakan fase gerak campuran butanol, asam asetat dan aquadest (BAA) dengan perbandingn 4 :1: 5. Berikut hasil KLT ekstrak etanol Pandan Species Baru Freycinetia sessiliflora Rizki

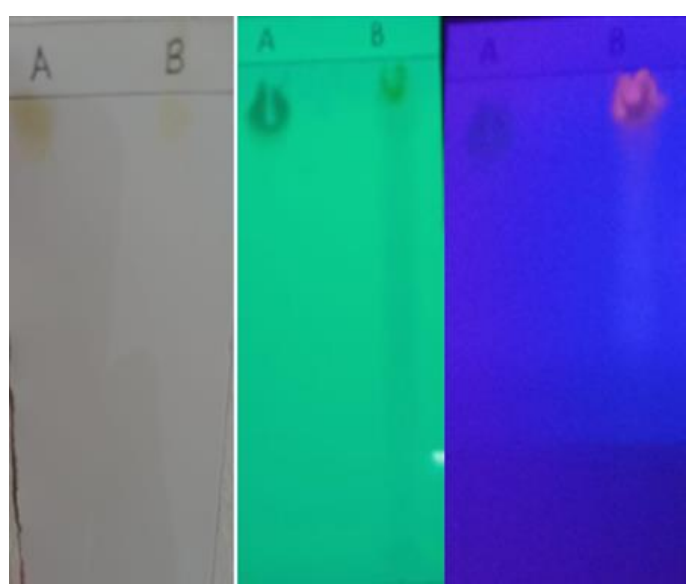

Gambar 2. Hasil KLT ( A : Standar

Quersetin, B : ekstrak Pandan \}

Eluen yang dipakai dalam KLT ialah campuran n-butanol : asam asetat : air 4: 1:5 yang mampu memberikan pemisahan. Eluen yang baik ialah eluen yng bisa memisahkan senyawa dalam jumlah yang banyak yang di tandai denga munculnya noda $^{6}$. Pemakaian kuersetin sebagai pembanding dikarenakan kuersetin merupakan senyawa yang paling luas penyebarannya dan $25 \%$ terdapat pada tumbuhan. Hasil KLT menunjukkan bahwa ekstrak etanol Pandan Species Baru Freycinetia sessiliflora Rizki dapat dipisahkan dengan fase gerak BAA (4 :1:5) senyawa semi polar dan non polar. senyawa - senyawa yang bersifat semi polar dan non polar akan keluar terlebih dahulu dari kolom karena sedikit terserap kedalam fase diam. pemisahn komponen sampel dengan kromatografi kolom menghasilkan 16 eluat yang ditampung dalam vial. eluat hasil kromatografi kolom dilihat pola nodanya menggunakan KLT dengan fase gerak BAA (4:1:5). Berikut hasil dari Kromatografi Kolom.

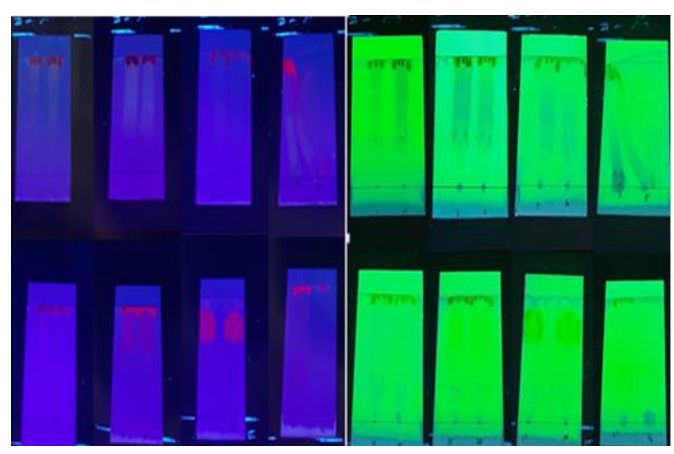

Gambar 3. Hasil KLT dari

Kromatografi Kolom 
Berdasarkan penelitian Mustapa, A $d k k$ (2019) yang menyatakan bahwa nilai $\mathrm{Rf}$ pembanding kuersetin yang digunakan sebagai pembanding memiliki range nilai $\operatorname{Rf} 0,69-0,81^{7}$. R $f$ senyawa flavonoid ekstrak etanol pandan yaitu 0,72-0,78 dengan bercak noda berwarna kuning kecoklatan. Nilai Rf dapat dijadikan bukti dalam mengidentifikasi suatu senyawa. Senyawa senyawa dengan nilai $R f$ yang sama atau hampir sama dapat menunjukkan bahwa senyawa tersebut memiliki karakteristik yang sama atau mirip ${ }^{8}$.

\section{KESIMPULAN}

Ekstrak etanol Pandan hutan Species Baru Freycinetia sessiliflora Rizki mengandung flavonoid.

\section{DAFTAR PUSTAKA}

1. Fitri , SR. Ferdinan, A. 2019. Skrinning Fitokimia Dan Uji Aktivitas Ekstrak Pandan Spesies Baru (Freycinetia Sessiliflora Rizki) Terhadap Bakteri Streptococcus Mutans, Eschericia Coli, Dan Staphylococcus Aureus Secara In Vitro.
2. Miller, A., L. (1996). Antioxidant Flavonoids : Structure, Function and Clinical Usage. Alt. Med. Rev. 1(2)

3. Artanti, N.Y., Ma'arifa \& M. Hanafi. 2006. Isolation and Identification of Active Antioxsidant Compound from Star Fruit Mistletoe Dendrophthoe pentandra (L) Miq, Ethanol Extract. Journal of Applied Sciences, 6(8): 16591663

4. Darsana, I.G.O., I.N.K. Besung, \& H. Mahatmi, 2012. Potensi Daun Binahong (Anredera cordifolia ( Tenore)Steenis) dalam menghambat Pertumbuhan Bakteri Escherichia coli secara invitro. Indonesia Medicus Veterinus 1 (3) : $337-351$.

5. Lenny, S. 2006. Isolasi dan Uji Bioaktifitas Kandungan Kimia Utama Puding Merah dengan Metoda Uji Brine Shrimp. FMIPA Universitas Sumatera Utara: Medan.

6. Harborne,J.B.1987, Metode Fitokimia Penutun dan Cara Modern Menganaisis Tumbuhan, a.b. Kosasih Padmawinata, ITB, Bandung

7. Mustapa, M.A, Taupik, M, Lalapa, AR 2019,Analisi Kadar Flavonoid total menggunakan spektrofotometri UV-VIS dalam Kulit Buah salak, journal Syifa Sciences and clinical research

8. Peter, L. 2010. Thin Layer Chromatography

Characterization of the Active Ingredients in Excedrin and Anacin. Stevens Institute of Technology. Hoboken 